* Caíque Tomaz Leite da Silva: Doutorando em Direito Público e Pós-Graduado em Direitos Humanos pela Universidade de Coimbra (POR). Especialista em Direito Civil e Direito Processual Civil. Banca Examinadora da American University (USA). Professor convidado do curso de Pós-graduação em Direitos Humanos da Universidade de Coimbra. Membro do grupo de trabalho encarregado da versão luso-brasileira da obra "Understanding Human Rights”, da Universidade de Coimbra e Editora Coimbra. Professor das Faculdades Integradas Antônio Eufrásio de Toledo (BRA). Professor da Escola Superior da Advocacia (ESA)._caique.thomaz@ hotmail.com

Artigo dedicado em memória do meu amigo de docência nas Faculdades Integradas Antônio Eufrásio de Toledo, Caio Shiguemy Cassiano Ishii o "Caio Shiro", aluno do programa de Mestrado em Direito Negocial da Universidade Estadual de Londrina - UEL.

\section{Do realismo à constitucionalização do direito internacional}

\author{
Constitutionalization REALISM OF \\ INTERNATIONAL LAW
}

\author{
Caíque Tomaz Leite da Silva *
}

Resumo: Inicialmente caracterizamos o paradigma vestefaliano nas relações entre os estados, enfatizando dentre suas características principais a territorialidade, a voluntariedade, e, no tocante às relações entre estado e súdito, a coisificação do homem fundamentada na soberania absoluta do estado. Posteriormente, no rescaldo da desmoralização do direito natural produtor da absolutização do direito positivo, o homem transcende à axiologia do ser-pessoa, o que o inseriu na órbita das relações entre os estados enquanto sujeito de direito autônomo. Tal axioma fragilizado pela absolutização da soberania adquire, também nas relações internacionais, uma tutela normativa constitucional, reconhecedora de sua personalidade já desvinculada da territorialidade exigida pela proteção diplomática. Sendo assim, o direto internacional constitucionaliza a tutela da ser-pessoa e limita a atuação dos protagonistas do direito internacional clássico através da proclamação da international bill of rights.

Palavras-chave: Territorialidade. Soberania absoluta. Constitucionalização. Bill of rights.

Abstract: Initially characterized the Westphalian paradigm in relations between states, stressing among its main features territoriality, willingness, and in relations between state and subject, the objectification of man based on the absolute sovereignty of the state . Later, in the aftermath of demoralization producer of natural law absolutism of positive law , man transcends the axiology of being- person, which entered the orbit of relations between states as subjects of autonomous right . This axiom weakened by the absolutism of sovereignty acquires, also in international relations, constitutional rules tutelage of his personality recognizer already detached from territoriality required by diplomatic protection. Thus, the direct tutelage of international constitucionaliza to be person and limits the actions of the protagonists of classic international law through the proclamation of the international bill of rights.

Keywords: Territoriality. Absolute sovereignty. Constitutionalization. Bill of Rights. 


\section{INTRODUÇÃO}

Através do emprego dos métodos indutivo e histórico colhemos indícios que permitiram a construção de dois paradigmas teoréticos de fundamentação do direito internacional: o realista ou vestefaliano, do direito internacional clássico; e o humanista, do direito internacional dos direitos humanos. Os eventos sociais e normativamente considerados permitiram captar, ainda, a superação do primeiro pelo segundo, que avança, ainda hoje, para um grau ótimo associado a constitucionalização do direito internacional, completando o ciclo de transformação do direito inter-nações em direito inter-gentes; O voluntarismo e a territorialidade deixam de exercer um papel preponderante na coexistência dos estados soberanos que deixam de gozar de uma soberania absoluta tanto no âmbito interno (relações verticais) como no âmbito internacional (relações horizontais), em razão da emergência de instrumentos e instituições de coercibilidade autônomos que funcionam em caráter transfronteiriço; A constitucionalização do direito internacional se apresenta como fenômeno relativamente recente e ainda pouco explorado nos manuais pátrios. Sua compreensão é condição para a internalização de externalidades jurisdicionais e normativas em todos os âmbitos de debate jurídico. Assim, o estudo da Declaração Universal dos Direitos Humanos, com sua já inquestionável força normativa, do Pacto Internacional de Direitos Civis e Políticos e do Pacto Internacional dos Direitos Econômicos, Sociais e Culturais, elementos da “international bill of rights”, deve ser associado aos estudos dos instrumentos normativos de tutela dos direitos fundamentais, vinculados ao constitucionalismo interno. Essa substituição de paradigmas gera reflexos sobre inúmeros setores sociais e sobre inúmeras construções dogmático-jurídicas e jurídico-políticas. Assim, por exemplo, no estudo dos sujeitos do direito internacional e suas fontes: a alteração do paradigma axiológico do direito internacional exige que outros sujeitos, além dos estados, sejam inseridos na órbita do direito internacional? Podem esses outros sujeitos produzirem instrumentos normativos vinculantes como direito internacional? O direito constitucional interno encontra no direito internacional um corresponsável pelo desempenho de suas principais atribuições ou, ao contrário, uma nova instância de poder político e normativo com quem disputa essa incidência política e normativa sobre os mesmos fatos? A constitucionalização do direito internacional fortalece o direito constitucional ou o direito internacional? Os resultados colhidos nesse breve ciclo de pesquisa foram pontualmente fixados no final trabalho. 


\section{DO REALISMO À HUMANIZAÇÃO DO DIREITO INTERNACIONAL}

O direito internacional dos direitos humanos emerge como disciplina autônoma no rescaldo da Segunda-Guerra Mundial. As atrocidades realizadas como forma de demonstração de força de uma ideologia intrinsecamente má foram as circunstâncias fáticas que fecharam o ciclo de uma era de relações internacionais em que os Estados figuravam como únicos e exclusivos sujeitos de direito para além de suas fronteiras, o que justificava, etimologicamente, que o direito que regulasse essas relações fosse chamado de direito inter-nações.

Esse modo de desenvolvimento das relações internacionais tinha como axioma absoluto a soberania do Estado. A soberania, nessa era chamada de realista, era duplamente absoluta: O Estado-nação era internamente soberano, o que implicava em dizer que aquele que detinha o poder soberano presentava o mais alto poder dentro da estruturação hierárquica de forças dentro da ordem de forças que se manifestavam dentro de Estado, como o poder popular, o poder militar, o poder eclesiástico, dentre outros. A soberania era, portanto, nas palavras de JEAN BODIN, o mais alto poder unificado dentro do Estado, pois ocupava o ápice da pirâmide de forças que se manifestavam dentro do Estado, condicionando-as e vinculando-as [suprema potestas superiorem non recognoscens]. Pouco importava, ao autor dos "Les Six Livres de la République”, 1576, que esse poder soberano fosse exercido por um (monarquia), por poucos (aristocracia), ou por muitos (democracia). Esse poder absoluto tinha como principais atribuições fazer leis e fazer guerras. As leis ordinárias positivas eram impostas independentemente de consentimento, como forma de demonstração de supremacia do poder soberano.

Esse poder absoluto ganhou projeção externa com a obra "Le Droit des Gens”, 1758, de EMMERICH DE VATTEL. Vattel foi responsável por projetar, nas relações internacionais, ou para as relações instauradas para além das fronteiras do Estado, essa perspectiva absoluta de soberania, que implicava em exclusividade de autoridade, porque o estado governava a si mesmo sobre sua própria autoridade e leis. Desse modo, todos os estados da comunidade internacional deveriam ser considerados igualmente soberanos e não deveria admitir como lícita qualquer intervenção em assuntos atinentes a sua soberania interna. O efeito dessa externalização da soberania absoluta foi a “coisificação” do homem, objeto de direito do estado, porque a autoridade de todos sobre cada membro pertencia ao estado. Não se reconhecia, no paradigma realista ou 
vestefaliano do direito internacional, a dignidade intrínseca do homem enquanto sujeito de individual e inalienável dignidade. Quando se olhava de fora para dentro dos estados, apenas um sujeito de direito era visualizado: o estado.

Os estados eram os únicos "sujeitos de direito" do direito inter-nações. Segundo Friedmann, "the States are the repositories of legitimated authority over peoples and territories. (...) This basic primacy of the State as a subject of international relations and law would be substantially affected, and eventually superseded, only if national entities, as political and legal systems, were absorbed in a world state." ${ }^{1} \mathrm{E}$ as aspas aqui se justificam porque não podemos falar propriamente em direito. Isso porque enquanto a comunidade internacional vinculava-se aos princípios da igualdade soberana e não ingerência em assuntos internos, como os estados não se sujeitavam a outro poder, em razão do caráter absoluto de sua soberania, ilimitada e incondicionada, bem como da ausência de um poder coercitivo internacional independente, a guerra passou a ser a forma "natural” de atuar nas relações internacionais.

Em 24 de Outubro de 1648, foram celebrados os tratados de paz de “Westphalia” (Tratado de Osnabrück e Tratado de Münster), que colocaram fim a Guerra dos Trinta Anos e erigiram a soberania a condição de pedra fundamental das relações internacionais. A coexistência de múltiplos estados somente seria possível se cada um deles fosse titular de um direito de idêntica dimensão: cada um é soberano em seu território, igual ao outro, e livre de qualquer interferência externa. Além de assegurar a liberdade e a igualdade religiosas e satisfazer os anseios territoriais de Suécia e França, os tratados de paz constituíram um marco do desenvolvimento do direito internacional porque exprimiram a adoção do voluntarismo e da territorialidade como duas grandes forças que atuavam para a compressão do poder soberano. Voluntarismo porque a igualdade soberana permitia que o estado atuasse conforme bem entendesse encontrando como limite a vontade do outro, ou impondo a sua vontade quando isso fosse possível. Territorialidade porque a soberania exigia aderência ao (seu) território, já que cada estado era soberano no seu território. Outro contributo prestado ao direito internacional público foi a criação do "treaty-making power", ou poder de celebrar tratados, instituído pelo artigo 65 do Tratado de Münster. Dentre os contributos dos Tratados de Paz de Vestefália para o moderno direito internacional, Casesse aponta o reconhecimento do protestantismo como religião, o que legitimava internacionalmente a existência de estados baseados na fé

${ }^{1}$ FRIEDMANN, Wolfgang. The Changing Structure of International Law. London, 1964, p. 213. 
luterana e calvinista; e o "birth of an international system based on a plurality of independent States, recognizing no superior autority over them”2.

Até a criação da Organização das Nações Unidas, em 1945, a guerra era, sem dúvida, a forma natural de afirmação do estado na comunidade internacional, embora o próprio Tratado de Münster, no artigo 123, estabelecia um sistema de segurança coletiva, mas absolutamente carente de algo que podemos chamar de instrumentos de coercibilidade autônomo. Havia primazia dos estados enquanto atores das relações internacionais, o que fazia com que o conflito fosse algo permanente e legitimador dos sistemas de poder existente. A comunidade internacional se sujeitava ao soberano absoluto que era, por isso, incondicionado externamente. Assim, o darwinismo era, digamos, a ideologia das relações internacionais, e a guerra era a expressão da natureza humana, o principal ator do equilíbrio político internacional ("balance of power”). A Carta da ONU, reestruturando a regulamentação do uso da força nas relações entre os estados, que se tentou limitar com o supracitado tratado, com o Concerto Europeu (1815) e com a Liga das Nações (1919), proíbe qualquer recurso à força física para solução de controvérsias.

Veja-se, portanto, que até a constituição da organização internacional supramencionada, o poder soberano só poderia, em tese, ser limitado internamente. Como a constituição e o aparelhamento de um estatuto propriamente de direito da comunidade internacional só se esboçou em termos realísticos após a Segunda-Guerra, a limitação do poder soberano, no paradigma vestefaliano, teria, necessariamente, de ser endógena.

Caberia às relações de poder instauradas dentro de estado encontrar alguma forma eficiente de fazer com que o poder soberano absoluto encontrasse certos critérios nas relações instauradas com os outros poderes. Essa necessidade de limitação do poder soberano constituiu o fundamento teorético de um movimento ideológico chamado de constitucionalismo. O constitucionalismo baseia-se em duas ideias fundamentais que convergem para a limitação do poder soberano: a) através da edição de uma "bill of rights" procura-se limitar o estado externamente, ou seja, nas relações em que o ente que exerce o poder de "imperium” instaura com aqueles que são sujeitos ao poder. O objetivo, aqui, é fazer com que a concessão de direitos aos súditos tenha por efeito restringir o âmbito de discricionariedade do poder supremo

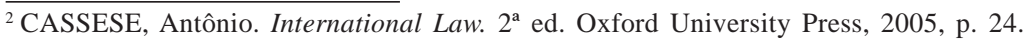


dentro do estado, especialmente no tocante a previsibilidade do comportamento do soberano e segurança jurídica quanto ao comportamento dos súditos; b) através da separação de poderes, almeja-se o estabelecimento de uma limitação interna ao estado, ou seja, o estado, enquanto organização formal que reúne inúmeras atribuições, precisa ser organizado de maneira relativamente harmônica, para que suas funções sejam exercidas de maneira satisfatória. ${ }^{3}$

As cartas de direitos gérmem da ideologia constitucionalista de regulamentação do estado, a "Magna Charta Libertatum", de 1215; a "Petition of Rights”, de 1628; o "Habeas Corpus Act”; e a "Bill of Rights”, de 1689, antecederam e constituíram o fundamento material para as primeiras constituições de que se têm notícia, tanto pela ideologia que exprimiam de limitação do poder através da concessão de direitos aos súditos, como pela regulamentação normativa que conferia ao ser a condição de pessoa, através da concessão de algumas prerrogativas exigíveis contra o soberano. Num primeiro momento, a dependência da coroa do poder econômico dos nobres, pagadores de impostos; e do poder político da igreja, com sua doutrina transcendental de vocação universalizante, fazia com que os direitos fossem menos direitos e mais privilégios, prerrogativas, em razão do seu carácter subjetivamente demarcado. O geral e abstrato passava longe dos primeiros documentos que concediam “direitos”, como os forais e cartas de franquias, muitos deles de alcance uni-subjetivo.

Sem alongar o discurso para que a prolixidade não nos faça perder o que aqui reputamos por essencial, retomo aquilo que é de nossa incumbência, o direito internacional dos direitos humanos. A Organização das Nações Unidas foi criada, em 1945, porque a ideologia constitucionalista já alastrada para quase todas as nações ditas civilizadas foi incapaz de subverter o realismo que imperava nas relações internacionais. A limitação dos estados através de suas constituições não constituía um fator impeditivo real de que o estado atuasse como bem entendesse em relação aos seus ainda não “cidadãos”. Isso porque a limitação tinha, tecnicamente, um caráter de autolimitação. Eis o paradoxo do constitucionalismo: se o estado tem o monopólio da força, e é, simultaneamente, o maior obstáculo à implementação dos direitos ditos fundamentais, normativamente assegurados em suas cartas constitucionais, a eficácia desses direitos só seria alcançada por intermédio de uma força exógena que limitasse, ao fim, o poder de autolimitação do estado.

\footnotetext{
${ }^{3}$ Declaração dos Direitos do Homem e do Cidadão, 1789, art. 16: "A sociedade em que não esteja assegurada a garantia dos direitos nem estabelecida a separação dos poderes não tem Constituição.”
} 
Veja-se, portanto, que a autolimitação pregada pela ideologia constitucionalista, porque de autolimitação mesmo se trata, mostrou-se, especialmente ao longo da primeira metade do século passado, incapaz de, sozinha, carregar a cruz antropológica de fazer com que os seres humanos fossem considerados igualmente dignos pela sua condição de humanidade. Nesse sentido, os patamares mínimos para que se tenha uma vida digna passam a ser devidamente reconhecidos pelo Direito Internacional dos Direitos Humanos, independente da origem que provenham. Passam a ser suscetíveis de proteção, pois, tanto na ordem interna como na ordem internacional.

É bem verdade que os primeiros passos para a humanização do direito internacional não foram tomados pelo direito internacional dos direitos humanos. Já na época do direito internacional clássico [realista] encontramos alguns antecedentes da autonomia da personalidade jurídica internacional do homem. Nesse sentido, muitos tratados que proibiam a escravidão e o tráfico de escravos foram firmados no século XIX, assim como os primeiros tratados internacionais sobre direito internacional humanitário, e a proteção dos direitos dos trabalhadores, inaugurada pelo direito internacional no século XX, com a Organização Internacional do Trabalho ${ }^{4}$. Observa-se, ainda, que o reconhecimento da personalidade para a responsabilidade internacional ocorreu ainda antes, havendo indícios de que já no século XVII o costume internacional autorizava a responsabilidade individual pelo crime de pirataria internacional. Todavia, esses eventos, embora permitissem a dissociação da relação entre indivíduo-estado, não podem ser considerados o ponto de viragem axiológica no direito internacional, haja vista que os interesses subjacentes ao reconhecimento tópico da personalidade individual nesses casos eram sempre vinculados aos estados, normalmente associado a seus interesses de natureza comercial.

Nesse cenário, a comunidade internacional entendeu, a duras penas, que não haveria estado, que não haveria constituição, que não haveria soberano, se uma terceira guerra dizimasse a humanidade. Assim, reunidos os esforços na Conferência de São Francisco, foi criada a Organização das Nações Unidas com o escopo de manter a paz e a segurança internacionais, desenvolver relações de amizade entre as nações, com base no princípio da igualdade de direitos e autodeterminação dos povos, promovendo e estimulando o respeito pelos direitos do homem, de modo que "international law is no longer jus inter potestates (a law governing only relations among sovereign entities). It also embraces

${ }^{4}$ Vide: GHANDHI, P. R. The Universal Declaration of Human Rights at Fifty Years: Its Origins, Significance and Impact. German Yearbook of International Law. Vol 41, 1998, pp. 210-220.

REVISTA DO DIREITO PÚBLICO, Londrina, v.9, n.1, p.135-162, jan./abr.2014 
individuals, by directly legitimizing, or issuing commands to, them. (...) it is gradually heading towards a civitas maxima (a human commonwealth encompassing individuals, States, and other aggregates cutting across the boundaries of States)"

Desse modo, o direito inter-nações assume um estatuto de direito intergentes $^{6}$, porque a pessoa humana foi erigida à condição de núcleo axiológico do direito internacional ${ }^{7}$, o que já defendia Hugo Grócio no século XVII ${ }^{8}$. O seu valor supremo é, agora e para todo o sempre, os direitos fundamentais do homem, a dignidade e o valor da pessoa humana, conforme as disposiç̧ões preambulares da Carta. A partir desta data, a solução pacífica das controvérsias torna-se postulado basilar do direito dito teimosamente, internacional, e a comunidade internacional inicia um processo de aparelhamento, em termos normativos, processuais e institucionais, para a proteção da pessoa, contra atos de seu estado caso necessário. A dimensão global adquirida pelos direitos humanos, em prol da efetiva consecução da dignidade da pessoa humana, passou a exigir uma proteção extensiva e generalizada do ser humano, de modo que os limites territoriais estatais não mais constituíssem óbices à sua tutela. Fala-se, portanto, em proteção internacional dos direitos humanos, e alguns conceitos que avocam essa dissociação entre ser-humano e estado, como o delicta juris gentium e jus cogens, como a proibição do uso da força, genocídio, discriminação racial, crimes contra a humanidade, pirataria internacional e escravidão .

${ }^{5}$ CASSESE, Antônio. International Law. 2a ed. Oxford University Press, 2005, p. 217.

${ }^{6} \mathrm{O}$ conceito de jus gentium tem sua origem associada ao direito privado romano, conforme LOMBARDI, Gabrio. Sul Concetto di "Ius Gentium". Roma: Istituto di Diritto Romano, 1947, pp. 3-390; CLARK, H. C. Jus Gentium - Its Origin and History. 14 Illinois Law Review, 1919, pp. 243-265 e 341-355. A partir do século XVI, passou a ser associado à humanidade como um todo, conforme GUGGENHEIM, Paul. Contribution à l'histoire des sources du droit des gens. 94 RCADI, 1958, pp. 21-23 e 25; MIELE, A. La Comunità Internazionale. Vol 1, $3^{\text {a }}$ ed. Torino: Giappichelli, 2000, pp. 75-80 e 89. ${ }^{7}$ BROWNLIE, Ian. Principles of Public International Law. 17 a ed. Oxford University Press, 2008, p. 65: aduz que não há um princípio geral de direito internacional que obsta o reconhecimento da personalidade jurídica do indivíduo, que pode, em algumas circunstâncias, figurar como sujeito de direito no âmbito internacional; CANÇADO TRINDADE, Antônio Augusto. A Humanização do Direito Internacional. Belo Horizonte: Del Rey, 2006, pp. 17 e 91 ; a p. 105: «l'être humain est sujet des droits et non simplement objet de protection, et ses droits lui son inhérents, et, par définition, antérieurs et supérieurs à l’État.»; for fim, o capítulo VI, pp. 129-142 : «La consolidación de la personalidad y capacidad jurídicas internacionales del ser humano en la agenda de los derechos humanos del siglo XXI».

${ }^{8}$ LAGHMANI, S. Histoire du droit des gens - du jus gentium impérial au jus publicum europaeum. Paris: Pédone, 2003, pp. 90-94; REMEC, P. P. The Position of the Individual in International Law according to Grotius and Vattel. The Hague: Nijhoff, 1960, pp. 221 e 243.

${ }^{9}$ Caso Barcelona Traction (segunda fase). ICJ Reports, 1970, §§ 33 e 34. A Corte Internacional de Justiça fez uma distinção entre obrigações oponíveis contra a outra parte contratante (estado) e obrigações oponíveis em relação à comunidade internacional como um todo ("towards the international 
A Carta da ONU trouxe em inúmeros dispositivos as expressões direitos fundamentais ou direitos do homem (preâmbulo, arts. 1, 13, 55, 56, 62, 68 e 76) com ausência de definição precisa. Isso porque o objetivo primordial era a constituição e aparelhamento de uma organização que tinha autonomia em relação à vontade soberana dos estados individualmente, e poder suficiente para se impor sobre eles em caso de utilização da força em violação ao princípio da solução pacífica das controvérsias. A Carta estabeleceu uma coexistência pacífica entre os Estados, fundada no respeito de suas vontades soberanas que detinham exclusividade de deliberação em aspectos econômicos, políticos e culturais, decorrência da exigência de respeito ao princípio maior da autodeterminação dos povos (art. 1.2). Desse modo, a Carta considerou ilícita qualquer intervenção da ONU ou dos outros Estados no aspecto de reserva absoluta de soberania, impermeável, até então, a valores jurídicos que excedessem o direcionamento absolutamente livre, salvo necessidade de medidas coercitivas para manutenção da paz (art. 2.7) ${ }^{10}$.

O artigo 55 estabelece uma responsabilidade da Organização das Nações Unidas em sede de direitos humanos, mas o único direito expressamente compreendido em tal dispositivo é a vedação da discriminação. O artigo 56, por sua vez, exige que os estados atuem, em conjunto ou separadamente, em cooperação com a ONU, para a promoção dos direitos humanos. Apesar da generalidade dos dispositivos, é possível afirmar que os artigos 55 e 56 estabelecem "autênticas obrigações jurídicas” em relação aos direitos humanos tanto para a ONU como para os Estados-membros ${ }^{11}$. A Corte Internacional de

community as a whole”); CASSESE, Antônio. International Law. $2^{\text {a }}$ ed. Oxford University Press, 2005, p. 262: o autor faz referência à "community obligation" em relação a obrigações consuetudinárias erga omnes que protegem valores fundamentais como a paz e os direitos humanos, e obrigações erga omnes contractantes criadas por tratados multilaterais que salvaguardam esses valores fundamentais. Nesses casos, qualquer outro estado "regardless of whether or not it has been materially or morally damaged by the breach" pode invocar a responsabilidade do violador.

${ }^{10}$ MARIE, Jean-Bernard; QUESTIAUX, Nicole. Article 55: alinéa c. In: La Charte des Nations Unies. Commentaire article par article. (direction: Alain Pellet et Jean-Pierre Cot). Economica: Paris, 1985, p. 870. Aduzem que o artigo 2.7 é uma disposição de geometria evolutiva, que fez com que os direitos humanos escapassem progressivamente do domínio reservado dos estados convertendo-se em matéria de interesse internacional. No mesmo sentido: CARRILLO SALCEDO, Juan Antonio. Soberanía de los Estados y Derechos Humanos en Derecho Internacional Contemporáneo. Madrid: Tecnos, 2001, p. 42.

${ }^{11}$ ISA, Felipe Gómez. La protección internacional de los derechos humanos. In: La protección internacional de los derechos humanos en los albores del S. XXI. Ed. Felipe Gómes Isa y José Manuel Pereza. Universidad de Deusto: Bilbao, 2004, p. 38; No mesmo sentido: HUMPHREY, John Peters. The UN Charter and the Universal Declaration of Human Rights. In: The International Protection of Human Rights. Evan Luard (ed). London, 1967, p. 42; GOODRICH, Leland M.; HAMBRO, Edvard; and SIMONS, Anne Patricia. Charter of the United Nations: Commentary and Documents. $3^{\text {a }}$ ed. New York, 1969, p. 381; JESSUP, Philip G. A Modern Law of Nations: An Introduction. New 
Justiça já se manifestou nesse sentido na opinião consultiva sobre a administração da Namíbia pela Africa do Sul ${ }^{12}$, ao aduzir que a política do apartheid implantada pela Africa do Sul violava as obrigações assumidas em relação à Carta. Singh, ex-presidente da CIJ (1985-1988), também se manifestou nesse sentido ao aduzir que "there is clear authority of the Court behind the interpretation of the human rights clauses of the Charter as creating binding legal obligations which was so correctly emphasised by Sir Hersch Lauterpacht several [sic] years

York, 1948, p. 91: "is already the law, at least for Members of the United Nations, that respect for human dignity and fundamental human rights is obligatory. The duty is imposed by the Charter, a treaty to which they are parties."; WRIGHT, Quincy. National Courts and Human Rights. The Fuji Case. AJIL, vol. 45, 1951, pp. 62-73: discorre sobre a imposição, do artigo 55, à proteção dos direitos humanos internamente; NEWMAN, Frank C. Interpreting the Human Rights Clauses of the Charter. HRJ, vol. 5, 1972, p. 283: "because of the UN Charter and its human rights clauses, every nation has obligations not to violate human rights”; SOHN, Louis B. The Human Rights Law of the Charter. Texas International Law Journal, vol. 12, 1977, p. 131: "The Charter is the cornerstone of international jus cogens, and its provisions prevail over all other international and domestic legislative acts. Should a state conclude a treaty or issue a legislative act or regulation which constitutes a gross violation of human rights, such a treaty or act would be clearly invalid as contrary to a basic and overriding norm of the Charter, and any tribunal, international or domestic, which might be asked to apply such a treaty, act or regulation, should refuse to do so.”; LAUTERPACHT, Hersch. International Law and Human Rights. New York: F. E. Praeger, 1950, chapter 9: "For the provisions of the Charter on the subject figure prominently in the statement of the Purpose of the United Nations. Members of the United Nations are under a legal obligation to act in accordance with these Purposes. It is their legal duty to respect and observe fundamental human rights and freedoms”. Ao longo do capítulo 9, o autor defende que esse dever é extraído dos artigos 13, que autoriza que a Assembleia Geral faça recomendações para a implementação de direitos humanos; 55, que exige respeito pelos direitos humanos; e 56, onde os estados se obrigaram a realizar ações, em conjunto ou separadamente, em cooperação com a ONU, para alcançar os propósitos do artigo 55. Assim, a Carta é um passo revolucionário em relação ao reconhecimento do indivíduo como sujeito do direito internacional; Em sentido contrário: HUDSON, M. Integrity of International Instruments. AJIL, vol. 42, 1948, pp. 105-107: "Charter is limited to setting out a programme of action for the Organization of the United Nations to pursue, in which the Members are pledge to co-operate"; KELSEN, Hans. The Law of the United Nations. London, 1950, p. 29: "the Charter does not impose upon the Members a strict obligation to grant to their subjects the rights and freedoms mentioned in the Preamble or in the text of the Charter.”; HENKIN, Louis. The United Nations and Human Rights. International Organization, vol. 19, 1965, p. 504: "hortatory phrases"; MOSKOVITZ, Moses. Human Rights and World Order. The Struggle for Human Rights. New York, 1958, p. 31: aduz que a Carta não é fonte de obrigações sobre direitos humanos.

${ }^{12}$ Legal Consequences for States of the Continued Presence of South Africa in Namibia (SW Africa) notwithstanding Security Council Resolution 276 (1970). ICJ Reports, 1971, §§ 129 e 131: (...) no factual evidence is needed for the purpose of deter-mining whether the policy of apartheid as applied by South Africa in Namibia is in conformity with the international obligations assumed by South Africa under the Charter of the United Nations (...) Under the Charter of the United Nations, the former Mandatory had pledged itself to observe and respect, in a territory having an inter-national status, human rights and fundamental freedoms for all without distinction as to race. To establish instead, and to enforce, distinctions, exclusions, restrictions and limitations exclusively based on grounds of race, colour, descent or national or ethnic origin which constitute a denial of fundamental human rights is a flagrant violation of the purposes and principles of the Charter. 
before the Court's pronouncement."13 Cassese, entretanto, aduz que a Carta não estabelece uma específica obrigação de agir singular para promoção e proteção dos direitos humanos (art. 56); o direito à autodeterminação dos povos foi proclamado apenas como um princípio guia para a ONU (arts. $1^{\circ}$ e $6^{\circ}$ ); o poder da Assembleia Geral em sede de direitos humanos era muito fraco, limitando-se à recomendações e condução de estudos, limitados, ainda, pelo art. 2.7; os direitos humanos foram teorizados não como um fim em si, mas como um meio para a manutenção da paz e segurança internacionais ${ }^{14}$. A preocupação maior da Carta, conforme sublinhado, não era ainda a proteção das pessoas, mas a coexistência harmônica entre Estados que se digladiaram por quase meio século, o que provocou a deterioração dos próprios Estados enquanto estruturas políticas-jurídicas de poder aptas a conceder e tutelar direitos fundamentais ${ }^{15}$. Isso porque a "soberanía externa, al coincidir con la igual soberanía de los demás Estados, genera una libertad salvaje que reproduce en el ámbito de la comunidad internacional el estado de naturaleza sin reglas que había sido negado y superado en el ámbito interno precisamente gracias a su institución. (...) en la medida en que son soberanos, se convierten en factores de guerra externa en la sociedad artificial de los Leviatanes que ha aparecido con ellos”16.

\section{A CONSTITUCIONALIZAÇÃO DO DIREITO INTERNA- CIONAL}

As ideias do constitucionalismo liberal não foram de todas descartadas embora se reconhecesse a fragilidade da autolimitação do estado promovida pelas constituições. Em verdade, o que realmente comprometia as boas ideias

\footnotetext{
${ }^{13}$ SINGH, Nagendra. Human Rights and the Future of Mankind. New Delhi: Vanity Books, 1981, p. 22.

${ }^{14}$ CASSESE, Antônio. International Law. $2^{\mathrm{a}}$ ed. Oxford University Press, 2005, p. 379.

${ }^{15}$ ANAND, R. P. Sovereign Equality of States in International Law. 197 RCADI, 1986, p. 164: aduz que somente com o fortalecimento da ONU e de outras organizações internacionais universais o realismo do império unilateral da força pode ser subvertido no direito internacional; Caso Nicaragua vs. United States. ICJ Reports, 1970, p. 97, § 181. Reconhece a fundamental importância da vedação do uso da força reconhecida pela Carta e pelo costume internacional.

${ }^{16}$ FERRAJOLI, Luigi. Derechos y garantías. La ley del más débil. 6a ed. Editorial Trotta, 2009, p. 135; Essa era a imagem da sociedade internacional apresentada por HOBBES, Thomas. Leviathan [1651]. Chapters XIII e XXI. Aduz que o detentor da soberania, em razão da sua independência, estaria numa situação perene de desconfiança mútua, como gladiadores, numa atitude belicosa. A liberdade do estado aduz, é simétrica àquela que cada homem teria se não houvesse estado nem leis civis; LOCKE, John. The Second Treatise of Government. An Essay Concerning the True Origin, Extent, and End of Civil Government [1689]. Chapters II e VII.
}

REVISTA DO DIREITO PÚBLICO, Londrina, v.9, n.1, p.135-162, jan./abr.2014 
que constituíam as limitações localizadas no estado era mesmo a ausência de limitações ao ente que limita e a ausência de um poder coercitivo que, de fato, o amedrontasse e vinculasse. Ideias como a catalogação de direitos fundamentais, soberania popular e separação de poderes, que tiveram como fundamento o reconhecimento da dignidade humana sobre o qual discorria a doutrina de direitos naturais foram, em boa medida, absorvidas pelo direito internacional dos direitos humanos (direito intergentes) nascente. Não é nenhum exagero dizer que o direito internacional juntou as peças de uma ideologia de limitação do estado assustada, fragmentada e escondida porque foi instrumentalizada para o mal agir.

Desse modo, embora seja relativamente recente a utilização da expressão constitucionalização do direito internacional, em referência ao modo como se organiza e desenvolve o direito internacional em termos de um sistema supraconstitucional, com pretensão de supremacia de suas disposições sobre as disposições dos estados ${ }^{17}$, em razão de fundamentação precedente em valores fundamentais que devem ser considerados como erga omnes, a origem dos axiomas consagrados normativamente através dos principais instrumentos normativos consagrados à escala global nos remete, sem dúvida, ao patrimônio acumulado ao longo do desenvolvimento do constitucionalismo. ${ }^{18}$

Vários são os argumentos que nos permitem estabelecer essa correlação. Trataremos, no presente tópico, do principal deles: a "International Bill of Rights”. Criada a Organização das Nações Unidas, foi constituída uma Comissão de Direitos Humanos, em 1946, como órgão subsidiário do Conselho Econômico e Social (ECOSOC), presidida por Eleanor Roosevelt, que tinha por incumbência a elaboração de um documento que declarasse, objetivamente, e, em termos de obrigação internacional, os direitos universalmente gozados pelos seres humanos pela sua dignidade intrínseca, ou as considerações básicas

\footnotetext{
${ }^{17}$ CASSESE, Antônio. International Law. $2^{\text {a }}$ ed. Oxford University Press, 2005, p. 217: o direito internacional "tending to become, more than a jus inter partes (a body of law governing relations among subjects 'in a horizontal manner'), a jus super partes (a corpus of legal standards regulating international dealings 'from above')".

${ }^{18}$ FASSBENDER, Bardo. The United Nations Charter as Constitution of the International Community. Columbia Journal of Transnational Law, 37, 1998, p. 529; DUPUY, Pierre-Marie. The Constitutional Dimension of the Charter of the United Nations Revisited. Max Planck Yearbook of United Nations Law, 1, 1997, p. 1; TOMUSCHAT, Christian. International Law as the Constitution of Mankind. In: International Law on the Eve of the Twenty-first Century views from the International Law Commission. New York: United National Publication, 1997, p. 37; BRUNKHORST, H. Solidarität, Von der Bürgerfreundschaft zun globalen Rechtsgenossenschaft. Frankfurt am Main: Suhrkamp, 2002, p. 216; MOHRS, Th. Vom Weltstaat. Hobbes' Sozialphilosophie, Soziobiologie, Realpolitik. Berlin: Academic Verlag, 1995, p. 337; HÖFFE, Otfried. Some Kantian reflections on a world republic. Kantian Review, 2, 1998, p. 51.
} 
de humanidade. Os direitos humanos foram inseridos nas relações internacionais como uma "subversive theory" que forçava os estados a atuar com responsabilidade em relação aos seus nacionais, limitava sua ordem legal interna e a configuração tradicional do direito internacional ${ }^{19}$.

René Cassin, que teve participação ativa no processo de elaboração da Declaração Universal, já no início da década de 40 escrevia sobre a necessidade de conferir aos direitos humanos uma perspectiva universal, através da criação de regras comuns a todos os seres humanos, a nível regional e universal, que colocassem o ser-humano antes do estado, leviatã que atuava contra o homem e contra a comunidade humana ${ }^{20}$. Antes de Cassin, o Institut de Droit International aprovou uma "Déclaration des droits internationaux de l'homme", em Nova Iorque, 1929, fruto do trabalho do presidente da comissão, André Mandelstam ${ }^{21}$. Em 10 de dezembro de 1948 foi, enfim, celebrada a Declaração Universal dos Direitos Humanos, com redação do próprio Cassin. A Declaração estabeleceu objetivamente um imenso rol de direitos que por seu caráter de fundamentalidade, deveria ser assegurado à escala global. Ocupouse da proibição geral de discriminação (art. 2), direitos civis (arts. 3-21) e direitos econômicos, sociais e culturais (arts. 22-28). Nos termos do preâmbulo a “dignidade inerente a todos os membros da família humana e dos seus direitos iguais e inalienáveis constitui o fundamento da liberdade, da justiça e da paz no mundo”.

A Declaração Universal dos Direitos Humanos completa a demolição do patrimônio jurídico consolidado com os Tratados de Paz de Vestefália, cuja ruína iniciara-se com a criação da Organização das Nações Unidas e vinculação ao princípio da solução pacífica das controvérsias, pois o artigo 2.6 da Carta autoriza que a ONU assegure que os não-membros atuem de acordo com seus princípios sempre que necessário, para a manutenção da paz e segurança

\footnotetext{
${ }^{19}$ CASSESE, Antônio. International Law. 2a ed. Oxford University Press, 2005, p. 375.

${ }^{20}$ CASSIN, René. L'État-Léviathan contre l'homme et la communauté humaine. Les Nouveaux Cahiers, 1940, pp. 13-16.

${ }^{21}$ Annuaire de l'Institut de Droit International. Vol. II. New York, 1929, pp. 112 e 117: "dans la conscience du monde moderne, la souveraineté de tous les États doit être limitée par le but commun de l'humanité. (...) La protection des droits de l'homme est le devoir de tout État envers la communauté internationale. (...) Il s'agit de proclamer les droits que la conscience du monde civilisé reconnaît aux individus en tant qu'hommes.”; MANDELSTAM, André. La protection internationale des droits de l'homme. RCADI, 1931-IV, pp. 206 e 218. O autor defendia a necessidade do reconhecimento internacional dos direitos humanos como ponto de partida para uma nova era de desafio à ideia de soberania absoluta dos estados. Para mais antecedentes à Declaração Universal, vide: BURGERS, J. H. The Road to San Francisco: the Revival of the Human Rights Idea in the Twentieth Century. Human Rights Quarterly, Vol. 14, 1992, pp. 447-477.
}

REVISTA DO DIREITO PÚBLICO, Londrina, v.9, n.1, p.135-162, jan./abr.2014 
internacionais, desafiando, desse modo, o princípio da voluntariedade nas relações internacionais. Por sua vez, a Declaração constitui-se em termos de proposição de caráter jurídico que aspira universalidade pelo seu pressuposto ou razão fundamentante, de modo que desafia o princípio da territorialidade ao conferir um papel central ao indivíduo. Essa perspectiva onto-antropológica do direito internacional inverte a relação entre fim e meio [instrumento] que existia no direito internacional clássico. Longe de ter um poder de vida e morte sobre seu cidadão, o estado transforma-se num meio para o livre e integral desenvolvimento de sua personalidade. 'L'État dans le monde n’est qu'un moyen en vue d'une fin, la perfection de l'humanité”22.

Mais do que uma mutação de paradigmas, a Declaração Universal dos Direitos Humanos marca o início do processo de redução progressiva do âmbito de reserva exclusiva de soberania do estado ["ridefinizione del concetto di sovranità nazionale"23], porque coloca o ser humano como ente universal ("homens livres e iguais”), estabelecendo parâmetros objetivos e supranacionais de respeito a essa universalidade. Assim, a proteção e a promoção dos direitos humanos deixa de ser tarefa exclusiva do direito constitucional interno ${ }^{24}$, havendo uma redefinição "di dimensione soggettive ed oggettive esistenti ed inoltre come espressione di autointegrazione ed eterointegrazione del sistema costituzionale" ${ }^{25}$. É bem verdade que a Declaração não era entendida como dotada de força normativa ${ }^{26}$ que vinculasse ou gerasse obrigações internacionais aos Estados

\footnotetext{
${ }^{22}$ Annuaire de l'Institut de Droit International. Vol. II. New York, 1929, pp. 112.

${ }^{23}$ PANEBIANCO, Mario. Iura humanitatis: diritti umane e "nuovi" diritti fondamentali. Revista Internazionale dei diritti dell'uomo. Ano XIV, 2001, p. 121

${ }^{24}$ ISA, Felipe Gómez. La protección internacional de los derechos humanos. In: La protección internacional de los derechos humanos en los albores del S. XXI. Ed. Felipe Gómes Isa y José Manuel Pereza. Universidad de Deusto: Bilbao, 2004, pp. 23 e 25.

${ }^{25}$ PANEBIANCO, Mario. Iura humanitatis: diritti umane e "nuovi" diritti fondamentali. Revista Internazionale dei diritti dell’uomo. Ano XIV, 2001, p. 124.

${ }^{26}$ LAUTERPACHT, Hersch. International Law and Human Rights. New York: F. E. Praeger, 1950, p. 408: "The language of the Universal Declaration, the circumstances and the reasons of its adoption, and, above all, the clearly and emphatically expressed intention of the States, Members of the United Nations, who voted for the Resolution of the General Assembly, show clearly that the Declaration is not by its nature and by the intention of its parties a legal document imposing legal obligations." O autor também duvida da força moral da declaração: "the moral authority and influence of an international pronouncement of this nature must be in direct proportion to the degree of sacrifice of the sovereignty of States which it involves (...) The Declaration does not purport to imply any sacrifice of the sovereignty of the State on the altar of the inalienable rights of man" (p. 419); BROWNLIE, Ian. Principles of Public International Law. $17^{\mathrm{a}}$ ed. Oxford University Press, 2008, p. 565; CASSESE, Antônio. International Law. $2^{\text {a }}$ ed. Oxford University Press, 2005, p. 381; O próprio grupo de trabalho encarregado de elaborar medidas de implementação para a futura declaração e convenções pronunciou-se no sentido de que a primeira não teria força normativa: Report of the Commission on Human Rights. Third Year: Sixty-Session, Supplement $n^{\circ} 1,1948$ [E/600, 17 December 1947], p. 34: "It even arrived at the conclusion that the question of implementation had
} 
que a assinaram, não havendo, ainda, uma efetiva submissão jurídico-normativa dos Estados ao direito internacional dos direitos humanos, mas a Declaração Universal constituiu um "unitary and universally valid concept of what values all States should cherish within their own domestic orders"27.

A verdade é que a abrangência de seus preceitos somada aos traumas das duas grandes guerras erigiu suas disposições a condição de programas que deveriam ser implementados pelos estados aderentes, que se abstraíram das discussões acerca dos fundamentos suprapositivos dos direitos humanos em prol da aceitação de sua universalidade. Partiu-se do consenso em torno da natureza humana, exatamente por isso os preceitos meramente declarados se consolidaram no âmbito normativos dos estados através de variados instrumentos jurídicos internos. As normas peremptórias de direito internacional dos direitos humanos "are gradually constituting the constitutional principles of the world society" 28 . Nesse sentido, a proposta de criação de uma "World Court of Human Rights”29 é descrita como a peça que falta no sistema global de proteção aos

much more to do with the Convention than with the Declaration. The latter indeed was in the last analysis to take the form of a recommendation by the General Assembly of the United Nations, and was consequently not legally binding in the strict sense of the term. It therefore appeared to the Working Group a manifest impossibility to contemplate measures for the fulfillment of an obligation that was not one.”; WHITEMAN, Marjorie Millace. Digest of International Law. Vol. 5. Department of State Publications. Washington DC., 1965, p. 243. Aduz que Eleanor Roosevelt, Presidente da Comissão de Direitos Humanos e representante dos Estados Unidos na Assembleia Geral, no mesmo dia da adoção da Declaração Universal, se manifestou no sentido de que a declaração não era um tratado ou acordo internacional ("agreement”), não era uma declaração de direitos ou obrigações jurídicas, mas princípios básicos de direitos humanos e liberdades que serviriam de ideal comum pelos quais todos os povos e nações deveriam se esforçar; United Nations. Economic and Social Council. E/CN.4/147, 16 June 1948. René Cassin, representante da França na Comissão de Direitos Humanos, peticionou à Eleanor Roosevelt afirmando que: “(...) human rights which existed before the Charter of the United Nations, a fortiori exist long before we formulate them in the Declaration. Nor must it be forgotten that a Declaration, basic instrument of the General Assembly, implies certain aspects which are binding per se, for exemple, the decision of the United Nations to offer its assistance to States Members (...). In other respects, however, the Declaration will have the character of a recommendation. Such will be the case when it calls on States Members gradually to bring their legislation into conformity with the principles formulated in it” (p. 1). Em suas considerações finais, Cassin aduz que a obrigação dos estados de implementação dos direitos humanos pode ser deduzida da Carta da ONU: "the States Members of the United Nations, in signing the Charter, have given a positive pledge to work for the effective respect of human rights in co-operation with the United Nations; that is the unshakeable foundation of any measure to be applied internationally.” (p. 8).

${ }^{27}$ CASSESE, Antônio. International Law. 2a ed. Oxford University Press, 2005, p. 381.

${ }^{28}$ CASSESE, Antônio. A Plea for a Global Community Grounded in a Core of Human Rights. In: Realizing Utopia. The Future of International Law. Ed. Antônio Cassese. Oxford University Press, 2012, p. 136.

${ }^{29}$ KOZMA, J.; NOWAK, M.; e SCHEININ, M. A World Court of Human Rights - Consolidated Statute and Commentary. Vienna: Neuer Wissenschaftlicher, 2010; CLAPHAM, Andrew. Overseeing Human Rights Compliance. In: Realizing Utopia. The Future of International Law. Ed. Antônio Cassese. Oxford University Press, 2012, p. 323. Vide capítulo 5: "Arriving in utopia: a World Court for Human Rights”; Na mesma coletânea: EVANS, Malcolm. The Future(s) of Regional Courts on

REVISTA DO DIREITO PÚBLICO, Londrina, v.9, n.1, p.135-162, jan./abr.2014 
direitos humanos, que se somaria às atividades do Alto-Comissariado das Nações Unidas para os Direitos Humanos e o Tribunal Penal Internacional. Não deixa de ser paradoxal o fato de que o direito internacional dos direitos humanos pune pessoas - não deixando qualquer dúvida sobre o reconhecimento e autonomia de sua personalidade - e deixa os estados sujeitos a mecanismos de controle como o sistema de relatórios, subordinado, nos mais das vezes, a vicissitudes políticas.

Atualmente, contudo, há relativo consenso entre os internacionalistas quanto a força obrigatória da Declaração, no sentido de que o documento constitui, em si, uma interpretação autorizada das obrigações de direitos humanos descritas na Carta da ONU em $1945^{30}$, sendo que a dúvida circunscreve-se ao processo através do qual a Declaração tornou-se hard law, bem como quais de suas disposições seriam imediatamente exequíveis. É inegável que muitas das disposições do documento preenchem os requisitos para a configuração de um costume internacional ${ }^{31}$ : a opinio juris é verificada pelo fato de que o documento foi aprovado sem qualquer voto contrário, e a convicção da obrigatoriedade foi construída ao longo de meio século de práticas nacionais e internacionais dos estados em suas relações diplomáticas e cortes internacionais ${ }^{32}$. O UN Office of Legal Affairs reconheceu que "in view of the greater solemnity and significance of a declaration, it may be considered to impart, on behalf of the organ adopting it, a strong expectation that Members of the international community will abide by it. Consequently, insofar as the

Human Rights, p. 272: duvida da sensatez e da possibilidade pragmática de tal aspiração; Report of the Commission on Human Rights. Third Year: Sixty-Session, Supplement $n^{\circ} 1,1948$ [E/600, 17 December 1947], pp. 48-49. A Comissão chegou a considerar a hipótese de que a implementação dos tratados internacionais de direitos humanos fosse realizada através de um controle judicial. Dentre as propostas, salienta-se a da Austrália, de criação de uma Corte Internacional de Direitos Humanos, com adesão da Bélgica e Irã, ao passo que a Índia e o Reino Unido defendiam que essa atribuição fosse conferida à Corte Internacional de Justiça. Os Estados Unidos demonstraram preocupação com a hipótese do estabelecimento da um órgão jurisdicional dificultar uma adesão ampla ao tratado.

${ }^{30}$ LAUTERPACHT, Hersch. International Law and Human Rights. New York: F. E. Praeger, 1950, p. 408: "maintain that a document contains an authoritative interpretation of a legally binding instrument is to assert that former document itself is as legally binding and as important as the instrument which it is supposed to interpret." (p. 408).

${ }^{31}$ HUMPHREY, John P. The International Bill of Rights: Scope and Implementation, 17 Wm. \& Mary L. Rev, 1976, p. 529; WALDOCK, Humphrey. Human Rights in Contemporary International Law and the Significance of the European Convention. ICLQ, $\mathrm{n}^{\circ} 11,1965$, pp. 1 e 15; SOHN, Louis B. The Human Rights Law of the Charter. Texas International Law Journal, vol. 12, 1977, p. 133: "Today the Declaration not only constitutes an authoritative interpretation of the Charter obligations but also a binding instrument in its own right, representing the consensus of the international community on the human rights which each of its members must respect, promote and observe."

${ }^{32}$ HUMPHREY, John P. The Universal Declaration of Human Rights: its History, Impact and Juridical Character. In: Human Rights: Thirty Years After the Universal Declaration (ed. B. G. 
expectation is gradually justified by State practice, a declaration may by custom become recognized as laying down rules binding upon States"33. No caso Barcelona Traction $^{34}$, por exemplo, após distinguir as obrigações baseadas no princípio da reciprocidade e as obrigações erga omnes, a Corte Internacional de Justiça aponta como fontes desse tipo especial de obrigação "international instruments of a universal or quase-universal character”. A Declaração Universal, indubitavelmente, preenche os requisitos exidos pela CIJ para que seja considerada fonte de obrigações erga omnes, pois é um instrumento internacional universal. No caso concernente aos membros do corpo diplomático e consular dos Estados Unidos no Irã ${ }^{35}$, a Corte Internacional de Justiça declarou expressamente que a violação da Declaração Universal poderia ser fonte de uma ilegalidade internacional, colocando-a no mesmo patamar que as obrigações internacionais que emanam da Carta da ONU: "wrongfully to deprive human beings of their freedom and to subject them to physical constraint in conditions of hardship is in itself manifestly incompatible with the principles of the Charter of the United Nations, as well as with the fundamental principles enunciated in the Universal Declaration of Human Rights” (negrito meu). Na Primeira Conferência Mundial sobre Direitos Humanos, em Teerã, 1968,

Ramcharan). The Hague, 1979, p. 33: "the Declaration is now part of the law of nations and therefore binding on all states whether they voted for it or not, this is not because it was adopted by the Assembly, important as that may have been, but for other reasons including subsequent events and the emergence of a juridical consensus evidenced by the practice of states that the Declaration is now, whatever the intention of its authors may have been in 1948, binding as part of the law of nations". No mesmo sentido se manifestou o Secretário Geral da ONU: "the Declaration not only constitutes an authoritative interpretation of the Charter obligations but also a binding instrument in its own right, representing the consensus of the international community on the human rights which each of its members must respect, promote and observe." (UN Doc. A/720/Add.1, 1968, p. 13); Fact Sheet No.2 (Rev.1), The International Bill of Human Rights, p. 8, aduz que a Declaração Universal é obrigatória tanto para os estados que retificaram os Pactos, como para os estados que não os ratificaram. Apenas os Pactos é que sujeitam ao princípio da voluntariedade: "Thus, for more than 25 years, the Universal Declaration on Human Rights stood alone as an international "standard of achievement for all peoples and all nations". It became known and was accepted as authoritative both in States which became parties to one or both of the Covenants and in those which did not ratify or accede to either. Its provisions were cited as the basis and justification for many important decisions taken by United Nations bodies. (...) the very existence of the Covenants, and the fact that they contain the measures of implementation required to ensure the realization of the rights and freedoms set out in the Declaration, gives greater strength to the Declaration (...) Moreover, the Universal Declaration is truly universal in scope, as it preserves its validity for every member of the human family, everywhere, regardless of whether or not Governments have formally accepted its principles or ratified the Covenants. On the other hand, the Covenants, by their nature as multilateral conventions, are legally binding only on those States which have accepted them by ratification or accession.; (negrito meu)

${ }^{33}$ UN Doc.E/CN.4/L.610, 1962.

${ }^{34}$ Caso Barcelona Traction (segunda fase). ICJ Reports, 1970, §§ 33 e 34.

${ }^{35}$ Caso United States Diplomatic and Consular Staff in Tehran. ICJ Reports, 1980, § 91. 
com a participação de 84 estados, dentre eles Estados Unidos e China, os presentes concluíram que a Declaração Universal era obrigatória para a comunidade internacional, e que as graves violações de direitos humanos constituíam também violação da Carta da $\mathrm{ONU}^{36}$. Na Segunda Conferência, em Viena, 1993, os 171 estados, de forma unânime, "reaffirming their commitment to the purposes and principles contained in the Charter of the United Nations and the Universal Declaration of Human Rights"37.

A evolução jurídico-normativa do direito internacional dos direitos humanos exigia que as disposições da Declaração Universal fossem revestidas de objetividade jurídica imediatamente exequível, através da elaboração de um documento internacional multilateral obrigatório, o que levou à proclamação, no ano de 1966, do Pacto Internacional dos Direitos Civis e Políticos (PIDCP), que confere ao "homem livre universal” direitos de caráter predominantemente individuais, que exigiam um alto grau de abstenção por parte dos estados. A importância histórica do PIDCP reside na inserção da cláusula democrática, que exige dos estados, independentemente da forma e sistema de governo, que sejam orientados por um regime absolutamente democrático, o que consolida a figura humana como fim de todas as instituições. ${ }^{38}$

Observa-se que a neutralidade axiológica que geriu o consenso da Declaração Universal dos Direitos Humanos e da Carta da Organização das Nações Unidas começa a tomar conotações contratualistas nas relações entre homem e estado, pois ao exigir que os estados se orientem democraticamente, reforça a natureza instrumental de tutor das relações intersubjetivas e dos direitos humanos: se foi constituído com base no feixe de poder mantido pelo indivíduo

\footnotetext{
${ }^{36}$ Final Act of the International Conference on Human Rights, A/CONF.32/41, 1968. Ponto 2: "The Universal Declaration of Human Rights states a common understanding of the peoples of the world concerning the inalienable and inviolable rights of all members of the human family and constitutes an obligation for the members of the international community"; ponto 6: "States should reaffirm their determination effectively to enforce the principles enshrined in the Charter of the United Nations and in other international instruments that concern human rights and fundamental freedoms". ${ }^{37}$ Vienna Declaration and Programme of Action. Adopted by the World Conference on Human Rights in Vienna. A/CONF.157/23, 1993, parte I, § 3. Vide ainda § 33.

${ }^{38} \mathrm{O}$ artigo 21.3 da Declaração Universal aduz que a vontade do povo é o fundamento da autoridade dos poderes públicos e deve exprimir-se através de eleições honestas, periódicas, com sufrágio universal, igual e voto secreto; por sua vez, o artigo 25 do Pacto Internacional dos Direitos Civis e Políticos apresenta praticamente a mesma redação. A análise dessas disposições permite deduzir que a democracia é erigida à condição de elemento do estado, de modo que nenhum estado deve ser reconhecido pela comunidade internacional caso não seja democrático, independentemente do sistema e forma de governo. Por outro lado, ao aduzir que a vontade do povo é pressuposto da autoridade, parece abrir uma brecha para a desobediência civil caso a autoridade do poder público caminhe em direção contrária a consciência jurídica comunitária, bem ao estilo contratualista de Samuel Puffendorf.
} 
num estado de natureza, tem sempre responsabilidades perante estes. Deste modo, o PIDCP erigiu a democracia à condição de elemento do conceito de Estado e impôs uma diretriz de ingerência nos aspectos políticos, até então salvaguardados pela Carta da ONU como conteúdo de reserva exclusiva de soberania. Desse modo, mesmo que os direitos normativizados neste primeiro documento assumam vergonhosamente uma indumentária liberal, nós podemos falar que existe por parte do estado "responsibility to protect"39.

No mesmo ano e simultaneamente, foi celebrado o Pacto Internacional dos Direitos Econômicos, Sociais e Culturais. A intersecção se deu pelo motivo que constitui o fundamento do nosso discurso: dificuldade de constituição de um consenso em torno do objeto da convenção: aspectos econômicos, sociais e culturais. Os parâmetros deste instrumento são mais específicos que os do primeiro. Disposições acerca da igualdade entre os sexos, raças, necessidade de adoção de medidas positivas para concretizar as obrigações assumidas, dentre outros aspectos. A nota nomeadamente negativa fica por conta do princípio da progressiva realização (art. 2.1), que dispõe que os estados devem assegurar progressivamente os direitos reconhecidos no Pacto no máximo de seus recursos disponíveis. A denominação da cláusula como princípio da progressiva realização é um eufemismo que oculta a verdadeira natureza jurídica da disposição: trata-se de uma excludente de responsabilidade internacional porque levanta o caráter objetivo que os direitos consagrados no pacto adquiriram e permite que os estados constantemente se eximam de atuar progressivamente para a efetivação das disposições do Pacto, sem que, para isso, tenham de se valer do instituto da reserva. Se por um lado significou a evolução em termos de ampliação do rol de direitos dignos de proteção, por outro sua eficácia padeceu na tentativa de universalização, pois a excludente supracitada não estabeleceu um parâmetro material judicialmente exequível.

Em termos genéricos, observa-se o desenvolvimento de uma atividade expansiva do direito internacional desencadeada pela Declaração Universal, e uma ingerência progressiva em assuntos tratados como dogmas nas relações entre os estados desde 1648. A consolidação do Pacto Internacional de Direitos Econômicos, Sociais e Culturais, significou uma incursão do direito internacional dos direitos humanos no âmbito de reserva exclusiva de soberania do estado quanto aos aspectos econômicos, sociais e culturais, enquanto os direitos civis

${ }^{39}$ The Responsibility to Protect. Report of the International Commission on Intervention and State Sovereignty. International Commission on Intervention and State Sovereignty, 2001. Especialmente o capítulo 2: “A New Approach: "The Responsibility to Protect”, pp. 11-16.

REVISTA DO DIREITO PÚBLICO, Londrina, v.9, n.1, p.135-162, jan./abr.2014 
e políticos foram enrijecidos pelo Pacto Internacional de Direitos Civis e Políticos. Não deixa de ser paradoxal que os estados, em razão da ausência de consenso em relação aos direitos que constituiriam um único pacto, opondo liberalistas e socialistas, tenham estabelecido, no preâmbulo de cada um dos Pactos, o princípio da interdependência dos direitos humanos (civis, políticos, econômicos, sociais e culturais), confirmado pela Conferência de Teerã, de 1968, e de Viena, em 1993.

Os três documentos: Declaração Universal dos Direitos Humanos, Pacto Internacional de Direitos Civis e Políticos, e Pacto Internacional de Direitos Econômicos, Sociais e Culturais, constituem o que a Organização das Nações Unidas compreende como "International Bill of Rights". "Thus the International Bill of Human Rights represents a milestone in the history of human rights, a veritable Magna Carta" ${ }^{40}$. Os documentos são complementares, em razão da indivisibilidade e interdependência inúmeras vezes ressaltada nos próprios instrumentos jurídicos e nas duas conferências mundiais de direitos humanos supracitadas. A Declaração, embora tenha disposto de maneira ampla sobre direitos humanos de todas as categorias, não tinha por escopo, nem instrumento que regulamentasse a implementação de suas disposições, o que levou a edição dos dois Pactos, conferindo aos direitos anteriormente previstos forma normativa, bem como estabelecendo o sistema de relatórios como forma de controle.

\section{A “international bill of rights" assume nitidamente um papel} desempenhado pelas constituições internas na tutela de direitos fundamentais. A Declaração Universal dos Direitos Humanos, de $1948^{41}$, o Pacto Internacional de Direitos Civis e Políticos ${ }^{42}$ e o Pacto Internacional dos Direitos Econômicos, Sociais e Culturais, simplesmente externaram os direitos consagrados pelo constitucionalismo ocidental e os erigiram contra o estado, para tutela do novo núcleo axiológico do direito internacional: o ser pessoa. Desse modo, falamos em humanização do direito internacional. "il termine umanizzazione (...) si intende ricollegarsi all'ottica degli iura humanitatis come fattore costitutivo

\footnotetext{
${ }^{40}$ Fact Sheet No.2 (Rev.1), The International Bill of Human Rights, pp. 1, 8 e 9; HUMPHREY, John P. The International Bill of Rights: Scope and Implementation, 17 Wm. \& Mary L. Rev, 1976, pp. 527 e ss.;

${ }^{41}$ Resolução da Assembleia Geral da ONU 217 A (III), de 10 de dezembro de 1948. Sobre a natureza vinculante de suas disposições, a título de direito consuetudinário: os Casos Barcelona Traction, ICJ Report, 1970 § 3; Namibia Opinion, ICJ Report, 1971, § 16, Separate Opinion, Judge Ammoun. ${ }^{42}$ Resolução da Assembleia Geral da ONU 2200 A (XXI), de 16 de dezembro de 1966, com entrada em vigor em 23 de março de 1976.
} 
dell'umanità che attribuisce a ciascuno uno status mundialis hominis di "cittadinanza del mondo"”, 43 . O artigo 103 da Carta da ONU firma, em linguagem constitucional $^{44}$, a primazia de suas obrigações sobre as demais obrigações internacionais, e constitui, para resguardo de suas disposições, um órgão jurisdicional internacional. Observa-se, entretanto, que a ideia de submissão dos estados independentes e soberanos a um único direito [direito das gentes] não é contemporânea ao direito internacional dos direitos humanos. Inúmeros filósofos que ofereceram contribuições teoréticas fundamentais para a construção da ideia de um direito entre nações já defendiam a existência de um “ius gentium” a vincular mais os povos que os estados [ente artificial], como Alberico Gentili4 ${ }^{45}$ e Hugo Grocio ${ }^{46}$. Francisco de Vitoria ${ }^{47}$ também defendia a ideia de que os poderes dos legisladores e reis deveria ser submetido ao império do direito.

\section{CONSIDERAÇÕES FINAIS}

a) O paradigma clássico [realista] do direito internacional, marcado nomeadamente pelos princípios da territorialidade, voluntariedade, caracterizado, ainda, pela soberania absoluta interna [Bodin] e externa [Vattel], foram produtoras da coisificação do homem [soberania interna absoluta] e da atuação externa exclusiva, baseada no recurso constante a força física para o desenvolvimento de relações entre os estados [soberania externa absoluta]. Tal paradigma consagrou um estado de natureza nas relações internacionais, simétrico àquele experimentado pelos homens antes da constituição de um ente que

\footnotetext{
${ }^{43}$ PANEBIANCO, Mario. Iura humanitatis: diritti umane e "nuovi" diritti fondamentali. Revista Internazionale dei diritti dell’uomo. Ano XIV, 2001, p. 144.

${ }^{44}$ CANÇADO TRINDADE, Otávio Augusto Drummond. A Carta das Nações Unidas. Uma Leitura Constitucional. Editora Del Rey, 2012.

${ }^{45}$ GENTILI, Alberico. De iure belli libri tres [1588]. Clarendon Press, Oxford, 1933, p. 13: "Imo ut rectio civitatis et legis latio est penes civitatis partem maiorem; ita orbis rectio est penes congregationem maioris partis orbis".

${ }^{46}$ GROCIO, Hugo. De iure belli ac pacis libri tres [1625]. Sijthoff, Lusguni Batavorum, 1919, p. 10: "si nulla est communitas quae sine iure conservari possit, quod memorabili latronum exemplo probabat Aristoteles, certe et illa quae genus humanum aut populos complures inter se colligat, iure indiget".

${ }^{47}$ VITORIA, Francisco de. De potestate civili [1528], en: Relaciones Teológicas del Maestro Fray Francisco de Vitoria. La Rafa, Madrid, 1934, II, p. 206: “Quaeritur tandem: An leges civiles obligent Legislatores, et maxime Reges. Videtur enim aliquibus quod non, cum sint supra totam Rempublicam, et nullus possit obligari, nisi a superiore; sed certius, et probabilius est, quod obligentur.”; a p. 207: "ius gentium non solum habet vim ex pacto et condicto inter hominies, sed etiam habet vim legis. (...) Habet enim totus orbis, qui aliquo modo est una respublica, potes-tate ferendi leges aequas et convenientes omnibus, quales sunt in iure gentium (...) Neque licet uni regno nolle teneri iure gentium: est enim latum totis orbis authoritate.”
} 
regulamentasse o uso da força e oferecesse critérios outros para a solução de litígios;

b) Esse paradigma colocou em risco a preservação da espécie humana e a preservação dos estados enquanto estruturas de poder, haja vista que este meio passou a colocar em risco a consecução do seu fim, que, ao menos em conotações contratualistas, colocava-o numa posição de garante em relação aos súditos [responsibility to protect]. A experiência das duas grandes guerras demonstrou a fragilidade moral dessa estrutura artificial, desapegada de qualquer parâmetro ético de atuação para realização do seu fim de desenvolvimento e preservação da personalidade humana. Fala-se, assim, em direito internacional dos direitos humanos, enquanto instrumento normativo de limitação da conduta do estado;

c) Essa responsabilidade de proteger foi então, normativamente regulamentada e limitada pelo direito internacional, que avoca a função de garante em face da impossibilidade do estado em concretizá-la através de uma mera autolimitação. Ao fazê-lo, se utiliza de percurso já conhecido tanto pelos estados que possuem sistemas jurídicos de matriz romano-germânica como do common law. Constrói-se, assim, em termos de uma hétero-limitação à soberania dos estados, através de disposições normativas que, a despeito de uma associação prima facie ao princípio da voluntariedade, ganha vida [e força] própria, se ocupando da limitação ao uso da força e da tutela de direitos consagrados pelo constitucionalismo como fundamentais;

d) A Carta da Organização das Nações Unidas não apresentou como objetivo primário a tutela do ser-humano, mas constituiu um marco quanto ao reconhecimento da personalidade humana e de direitos indispensáveis ao desenvolvimento dessa personalidade. A despeito disso, já impunha obrigações genéricas aos estados limitando o modo como se relacionavam com outros estados e com as pessoas. A Declaração Universal dos Direitos do Homem foi proclamada por Resolução da Assembleia Geral, sem nenhum voto contrário. A despeito de sua primária apatia normativa, tornou-se um documento de referência no estabelecimento de juízos de valoração quanto a condutas dos estados e outros sujeitos de direito internacional. Até que os Pactos conferissem força normativa aos direitos consagrados, o que ocorreu somente com início da vigência em 1976, a Declaração Universal foi, por quase três décadas, o referente internacional de moralização da relação estado-pessoa. Isso fez com que o seraí da declaração se tornasse animado por uma conjugação de fatores que levaram a doutrina e jurisprudência internacional a afirmar sua força normativa, seja 
enquanto interpretação das obrigações de direitos humanos previstos na Carta, seja enquanto costume internacional [general practice e opinio juris]. Desse modo, o Pacto Internacional de Direitos Civis e Políticos e o Pacto Internacional de Direitos Econômicos, Sociais e Culturais, apenas apresentam a mais-valia de colocar à disposição do já consagrado rol de direitos, instrumentos de implementação das obrigações estatais, repristinando a ideia originária da Comissão de Direitos Humanos de construir uma "international bill of rights" com uma estrutura tripartida, composta da Declaração Universal, os Pactos da Direitos Humanos, e uma série de medidas de implementação dos instrumentos proclamados.

\section{REFERÊNCIAS}

ANAND, R. P. Sovereign Equality of States in International Law. 197 RCADI, 1986.

Annuaire de l’Institut de Droit International. Vol. II. New York, 1929.

BROWNLIE, Ian. Principles of Public International Law. $17^{\mathrm{a}}$ ed. Oxford University Press, 2008.

BRUNKHORST, H. Solidarität, Von der Bürgerfreundschaft zun globalen Rechtsgenossenschaft. Frankfurt am Main: Suhrkamp, 2002.

BURGERS, J. H. The Road to San Francisco: the Revival of the Human Rights Idea in the Twentieth Century. Human Rights Quarterly, Vol. 14, 1992.

CANÇADO TRINDADE, Antônio Augusto. A Humanização do Direito Internacional. Belo Horizonte: Del Rey, 2006.

CANÇADO TRINDADE, Otávio Augusto Drummond. A Carta das Nações Unidas. Uma Leitura Constitucional. Editora Del Rey, 2012.

CARRILLO SALCEDO, Juan Antonio. Soberanía de los Estados y Derechos Humanos en Derecho Internacional Contemporáneo. Madrid: Tecnos, 2001. 
CASSESE, Antônio. International Law. $2^{\mathrm{a}}$ ed. Oxford University Press, 2005.

A Plea for a Global Community Grounded in a Core of Human Rights. In: Realizing Utopia. The Future of International Law. Ed. Antônio Cassese. Oxford University Press, 2012.

CASSIN, René. L'État-Léviathan contre l'homme et la communauté humaine. Les Nouveaux Cahiers, 1940.

CLAPHAM, Andrew. Overseeing Human Rights Compliance. In: Realizing Utopia. The Future of International Law. Ed. Antônio Cassese. Oxford University Press, 2012.

CLARK, H. C. Jus Gentium - Its Origin and History. 14 Illinois Law Review, 1919.

DUPUY, Pierre-Marie. The Constitutional Dimension of the Charter of the United Nations Revisited. Max Planck Yearbook of United Nations Law, 1, 1997.

EVANS, Malcolm. The Future(s) of Regional Courts on Human Rights. In: Realizing Utopia. The Future of International Law. Ed. Antônio Cassese. Oxford University Press, 2012.

Fact Sheet No.2 (Rev.1), The International Bill of Human Rights.

FASSBENDER, Bardo. The United Nations Charter as Constitution of the International Community. Columbia Journal of Transnational Law, 37, 1998.

FERRAJOLI, Luigi. Derechos y garantías. La ley del más débil. $6^{\mathrm{a}}$ ed. Editorial Trotta, 2009.

Final Act of the International Conference on Human Rights, A/ CONF.32/41, 1968. 
FRIEDMANN, Wolfgang. The Changing Structure of International Law. London, 1964.

GENTILI, Alberico. De iure belli libri tres [1588]. Clarendon Press, Oxford, 1933.

GHANDHI, P. R. The Universal Declaration of Human Rights at Fifty Years: Its Origins, Significance and Impact. German Yearbook of International Law. Vol 41, 1998.

GOODRICH, Leland M.; HAMBRO, Edvard; and SIMONS, Anne Patricia. Charter of the United Nations: Commentary and Documents. $3^{\mathrm{a}}$ ed. New York, 1969.

GROCIO, Hugo. De iure belli ac pacis libri tres [1625]. Sijthoff, Lusguni Batavorum, 1919.

GUGGENHEIM, Paul. Contribution à l'histoire des sources du droit des gens. 94 RCADI, 1958.

HENKIN, Louis. The United Nations and Human Rights. International Organization, vol. 19, 1965.

HOBBES, Thomas. Leviathan [1651].

HÖFFE, Otfried. Some Kantian reflections on a world republic. Kantian Review, 2, 1998.

HUDSON, M. Integrity of International Instruments. AJIL, vol. 42, 1948.

HUMPHREY, John Peters. The UN Charter and the Universal Declaration of Human Rights. In: The International Protection of Human Rights. Evan Luard (ed). London, 1967.

The International Bill of Rights: Scope and Implementation, 17 Wm. \& Mary L. Rev, 1976. 
The Universal Declaration of Human Rights: its History,

Impact and Juridical Character. In: Human Rights: Thirty Years After the Universal Declaration (ed. B. G. Ramcharan). The Hague, 1979.

ISA, Felipe Gómez. La protección internacional de los derechos humanos. In: La protección internacional de los derechos humanos en los albores del S. XXI. Ed. Felipe Gómes Isa y José Manuel Pereza. Universidad de Deusto: Bilbao, 2004.

JESSUP, Philip G. A Modern Law of Nations: An Introduction. New York, 1948.

KELSEN, Hans. The Law of the United Nations. London, 1950.

KOZMA, J.; NOWAK, M.; e SCHEININ, M. A World Court of Human Rights - Consolidated Statute and Commentary. Vienna: Neuer Wissenschaftlicher, 2010.

LAGHMANI, S. Histoire du droit des gens - du jus gentium impérial au jus publicum europaeum. Paris: Pédone, 2003.

LAUTERPACHT, Hersch. International Law and Human Rights. New York: F. E. Praeger, 1950.

LOCKE, John. The Second Treatise of Government. An Essay Concerning the True Origin, Extent, and End of Civil Government [1689].

LOMBARDI, Gabrio. Sul Concetto di “Ius Gentium”. Roma: Istituto di Diritto Romano, 1947.

MANDELSTAM, André. La protection internationale des droits de l'homme. RCADI, 1931-IV.

MARIE, Jean-Bernard; QUESTIAUX, Nicole. Article 55: alinéa c. In: La Charte des Nations Unies. Commentaire article par article. (direction: Alain Pellet et Jean-Pierre Cot). Economica: Paris, 1985. 
MIELE, A. La Comunità Internazionale. Vol 1, $3^{\text {a }}$ ed. Torino: Giappichelli, 2000.

MOHRS, Th. Vom Weltstaat. Hobbes‘ Sozialphilosophie, Soziobiologie, Realpolitik. Berlin: Academic Verlag, 1995.

MOSKOVITZ, Moses. Human Rights and World Order. The Struggle for Human Rights. New York, 1958.

NEWMAN, Frank C. Interpreting the Human Rights Clauses of the Charter. HRJ, vol. 5, 1972.

PENEBIANCO, Mario. Iura humanitatis: diritti umane e "nuovi" diritti fondamentali. Revista Internazionale dei diritti dell’uomo. Ano XIV, 2001.

REMEC, P. P. The Position of the Individual in International Law according to Grotius and Vattel. The Hague: Nijhoff, 1960.

Report of the Commission on Human Rights. Third Year: Sixty-Session, Supplement nº1, 1948 [E/600, 17 December 1947].

SINGH, Nagendra. Human Rights and the Future of Mankind. New Delhi: Vanity Books, 1981.

SOHN, Louis B. The Human Rights Law of the Charter. Texas International Law Journal, vol. 12, 1977.

The Responsibility to Protect. Report of the International Commission on Intervention and State Sovereignty. International Commission on Intervention and State Sovereignty, 2001.

TOMUSCHAT, Christian. International Law as the Constitution of Mankind. In: International Law on the Eve of the Twenty-first Century views from the International Law Commission. New York: United National Publication, 1997.

UN Doc. A/720/Add.1, 1968. 
UN Doc. E/CN.4/L.610, 1962.

United Nations. Economic and Social Council. E/CN.4/147, 16 June 1948.

Vienna Declaration and Programme of Action. Adopted by the World Conference on Human Rights in Vienna. A/CONF.157/23, 1993.

VITORIA, Francisco de. De potestate civili [1528], en: Relaciones Teológicas del Maestro Fray Francisco de Vitoria. La Rafa, Madrid, 1934.

WALDOCK, Humphrey. Human Rights in Contemporary International Law and the Significance of the European Convention. ICLQ, $n^{\circ} 11$, 1965.

WHITEMAN, Marjorie Millace. Digest of International Law. Vol. 5. Department of State Publications. Washington DC., 1965.

WRIGHT, Quincy. National Courts and Human Rights. The Fuji Case. AJIL, vol. 45, 1951.

Artigo recebido em: 05/12/2013 Aprovado para publicação em: 01/04/2014

Como citar: SILVA, Caíque Tomaz. Do realismo à constitucionalização do direito internacional. Revista do Direito Público. Londrina, v.9, n.1, p.135162, jan./abr.2014. DOI: 10.5433/1980-511X.2014v9 n1p135. 